\title{
Safety of Lienal Polypeptide Injection Combined with Chemotherapy in Treating Patients with Advanced Cancer
}

\author{
Xin-En Huang*, Lin Wang, Zhu-Qing Ji, Meng-Yan Liu, Ting Qian, Li Li
}

\begin{abstract}
Objective: To assess the safety of Liena polypeptide injection (produced by JILIN FSENS PHARMACEUTICAL CO.,LTD) combined with chemotherapy in treating patients with advanced cancers. Method: A consecutive cohort of patients with advanced cancers were treated with Liena polypeptide injection combined with chemotherapy. And chemotherapy for patients with advanced cancers were adopted from regimens suggested by NCCN guideline. Liena polypeptide injection was intravenously injected at a dosage of $2 \mathrm{ml}$ plus $100 \mathrm{ml}$ normal saline for continuous 7 days during chemotherapy as one course. After at least two courses of treatment, safety and side effects were evaluated. Results: There were 20 female and 14 male patients with advanced cancer recruited into this study, including 10 patients with breast, 8 patients with colorectal, 8 patients with lung, 4 patients with gastric, and 1 patient with esophageal cancer, as well as 1 patient with non-Hodgkin's lymphoma, 1 patient with low pharyngeal and 1 patient with urethral cancer. The median age of patients was 59 (40-82) years. Incidences of Grade 1 to 2 myelosuppression was observed in 5/34 patients, and Grade 1 to 2 elevation of hepatic enzyme was recorded in $3 / 34$ patients. Adverse effects on the gastrointestinal tract were documented in $5 / 34$ patients, and were Grade 1. No Grade 3-4 toxicities were diagnosed. No treatment related death was found. Conclusions: Liena polypeptide injection combined with chemotherapy was safe in treating several sites of tumors, that mainly included lung, colorectal and breast cancer. However, further study should be conducted to clarify the effectiveness of this treatment.
\end{abstract}

Keywords: Lienal polypeptide injection - chemotherapy - advanced cancer

Asian Pac J Cancer Prev, 16 (17), 7837-7841

\section{Introduction}

Worldwide investigation suggested that there were 14.1 million new cancer cases, 8.2 million cancer-related deaths, and 32.6 million people living with cancer (within five years of diagnosis) in 2012 (WHO, 2012). The incidence and mortality were 182.0/100,000 and $102.4 / 100,000$, respectively, while the 5-year prevalence was $625.0 / 100,000$. And it is estimated based on the incidence, population growth, and aging that new cancer cases will increase worldwide from 12.7 million in 2008 to 21.4 million in 2030 (Jemal A, 2011). With the implementation of early detection, prevention, screening, and treatment, the incidence and mortality of cancer recently declined (Ferlay J et al 2010; Liu et al 201). However, the size of population in China is estimated near 1.4 billion in 2010 (National Bureau of Statistics of China, 2011). On this background, the incidence of cancer and cancer-related mortality in China is also higher compared with other countries (Chen W et al, 2014). One important reason of this cancer risk in China is aging, with approximately $64 \%$ of the cancer patients aged more than 60 years (Ferlay J et al, 2010). Regarding treatment for cancer, surgery, chemotherapy, radiotherapy, as well as immunotherapy are mostly considered (Cheng $\mathrm{M}$ et al, 2013; Peng XH et al, 2008). Surgery, which involves removal of the tumor and the surrounding tissue, remains the most common treatment for various types of cancer. However, it could not be used to treat leukemia and lymphoma. Moreover, the combination of surgery with other therapies is necessary because most neoplasms could metastasize to other organs (Brannon-Peppas L et al, 2004; Ozols RF et al., 2006; Arruebo M et al, 2007). Chemotherapy is widely used to treat cancer with advanced stage. However, chemical substances is reported to suppress the immune system by diminishing immune cells, and is associated with various toxicities (Shurin MR et al, 2012).

Cancer immunotherapy is used to activate the immune system to treat cancer. The activity of immune cells, eg., macrophages, natural killer cells, dendritic, and T-cells, is enhanced by various immune activators, including cytokines, and immunological regimens (Rosenberg SA et al., 2004; Rosenberg SA et al., 2001; Serda RE et al., 2013). These immunological activators could increase anticancer activity by generating $\mathrm{T}$ helper 1 (Th1) cells and cytotoxic T-lymphocytes (CTLs).

According to this background, we hypothesize that 
Table 1. Characteristic of Recruited Patients

\begin{tabular}{|c|c|c|c|c|}
\hline $\begin{array}{l}\text { Hospital registration } \\
\text { number }\end{array}$ & $\begin{array}{c}\text { Gender } \\
\text { Male/Female }\end{array}$ & Age & Diagnosis & $\begin{array}{l}\text { Chemotherapy } \\
\text { with Liena polypeptides }\end{array}$ \\
\hline 228554 & M & 50 & Colorectal cancer & Irinotecan+Oxaliplatin+Raltitraxed \\
\hline 215446 & $\mathrm{~F}$ & 64 & Breast cancer & Paclitaxel+Cisplatin \\
\hline 229497 & $\mathrm{~F}$ & 57 & Lung cancer & Pemetrexed+Cisplatin \\
\hline 259143 & $\mathrm{~F}$ & 71 & Esophageal cancer & Xeloda+Nedaplatin \\
\hline 243869 & $\mathrm{~F}$ & 40 & Lung cancer & Pemetrexed+Lobaplatin+VM-26 \\
\hline 254729 & $\mathrm{~F}$ & 59 & Breast cancer & Herceptin+Paclitaxel \\
\hline 252911 & M & 57 & Gastric cancer & TS-1+Oxaliplatin \\
\hline 244763 & $\mathrm{~F}$ & 64 & Colorectal cancer & Pemetrexed+Oxaliplatin \\
\hline 263413 & M & 72 & Lung cancer & nano-Paclitaxel+Nadaplatin \\
\hline 165978 & $\mathrm{~F}$ & 64 & Breast cancer & nano-Paclitaxel \\
\hline 262700 & $\mathrm{~F}$ & 59 & Breast cancer & Epirubicine+cyclophasfemide \\
\hline 236374 & $\mathrm{~F}$ & 54 & Breast cancer & Herceptin+Xeloda \\
\hline 265617 & M & 51 & Colorectal cancer & Irinotecan+C-225 \\
\hline 266008 & $\mathrm{~F}$ & 61 & Lung cancer & Pemetrexed+Carboplatin \\
\hline 193066 & $\mathrm{~F}$ & 61 & Non Hodgkin's Lymphoma & CHOP \\
\hline 252915 & M & 74 & Colorectal cancer & Retitrexed+Oxaliplatin \\
\hline 214723 & M & 78 & Colorectal cancer & Irinotecan+Endostar+C-225 \\
\hline 253141 & M & 55 & Gastric cancer & Xeloda+Oxaliplatin \\
\hline 225507 & $\mathrm{~F}$ & 46 & Breast cancer & Herceptin+Novelbine+Cisplatin \\
\hline 254892 & $\mathrm{~F}$ & 51 & Breast cancer & Epirubicine+cyclophasfemide \\
\hline 252592 & $\mathrm{~F}$ & 69 & Breast cancer & Epirubicine+cyclophasfemide followed by Paclitaxel \\
\hline 252075 & M & 77 & Lung cancer & Pemetrexed+Cisplatin \\
\hline 246125 & $\mathrm{~F}$ & 60 & Lung cancer & Pemetrexed+Cisplatin+Irinotecan \\
\hline 227032 & M & 58 & Colorectal cancer & Pemetrexed+Oxaliplatin+Irinotecan \\
\hline 244135 & $\mathrm{~F}$ & 40 & Breast cancer & Pemetrexed+Cisplatin+Gemcitabine \\
\hline 228068 & M & 71 & Gastric cancer & Reltitrexed+Irinotecan \\
\hline 269681 & M & 42 & Colorectal cancer & FOLFOX \\
\hline 267454 & M & 82 & Lung cancer & TS-1+Nedaplatin \\
\hline 269434 & M & 55 & Low pharyngeal cancer & Cisplatin+Gemcitabine \\
\hline 269368 & $\mathrm{~F}$ & 70 & Urethral cancer & Docetaxel+Gemcitabine \\
\hline 268476 & $\mathrm{~F}$ & 71 & Colorectal cancer & Oxaliplatin+5-FU/CF \\
\hline 236374 & $\mathrm{~F}$ & 54 & Breast cancer & Zeloda+Herceptin \\
\hline 267403 & M & 58 & Gastric cancer & Docetaxel+Oxaliplatin \\
\hline 264883 & $\mathrm{~F}$ & 68 & Lung cancer & Docetaxel+Oxaliplatin+VM26 \\
\hline
\end{tabular}

liena polypeptide injection combined with chemotherapy could be established as an optimal schedule in treating Chinese patients with cancer.

\section{Materials and Methods}

\section{Eligiblility criteria}

Patients recruited in this study were required to be pathologically/ cytologically diagnosed with cancer in Jiangsu Cancer Hospital \& Research Institute; to sign an informed consent before treatment; to expose to long term chemotherapy or supportive care; to have a score of karnofsky performance status (KPS) $\geq 60$ with expectancy life span more than 3 moths; to be classified with no contraindications for chemotherapy; to have a routine blood test performed 0 to 3 days before chemotherapy and normal hematopoietic function as evidenced by white blood cell count 3000/ul and platelet count 100000/ul, normal hepatic function test (aspartate aminotransaminase and alanine aminotransferase less than 1.5 times of the upper limit of normal values), renal function test (serum total bilirubin $<1.5 \mathrm{mg} / \mathrm{dl}$ and creatinine $<1.5 \mathrm{mg}$ / dl). Exclusion criteria included history of alcoholic intoxication, diabetes, and patients who were pregnant or nursing. Chemotherapy was administered according to NCCN guideline. Liena polypeptide injection was intravenously injected at a dosage of $2 \mathrm{ml}$ plus $100 \mathrm{ml}$ normal saline for continuous 7 days during chemotherapy as one course. After at least two courses of treatment, safety and side effects were evaluated.

\section{Toxicity Evaluation}

The incidence rates of toxicity in this study were assessed at baseline and respectively after two cycles of treatment, the grade of toxicities was determined according to The National Cancer Institute Common Terminology Criteria for Adverse Events (NCI CTCAE; version 3 ).

\section{Results}

There were 20 female and 14 male patients with advanced cancer recruited into this study, including 10 patients with breast, 8 patients with colorectal, 8 patients with lung, 4 patients with gastric, and 1 patient with esophageal cancer, as well as 1 patient with nonHodgkin's lymphoma, 1 patient with low pharyngeal and 1 patient with urethral cancer (table 1). The median age of patients was 59 (40-82) years. Incidences of Grade 1 to 2 myelosuppression was observed in $5 / 34$ patients, and Grade 1 to 2 elevation of hepatic enzyme was recorded in $3 / 34$ patients. Adverse effects on the gastrointestinal 
tract were documented in 5/34 patients, and were Grade 1. No Grade 3-4 toxicities were diagnosed. No treatment related death was found.

\section{Discussion}

Cancer is a group of diseases with deregulated growth of abnormal cells. The reason for this uncontrolled growth is a series of mutations that cause aberrant expression of gene products essential for regulating proliferation, survival, and growth activities of cells; and further, cause basic biological changes of cells: the ability to respond to growth signals, engage cell death programs to eliminate unnecessary, excess or damaged cells, and the formation of new blood vessels and ability to invade tissue. Thus, clinicians and researchers try to find effective therapeutic approaches that could eliminate cancerous cells, meanwhile protecting normal, healthy tissues. In the field of cancer treatment in China, significant progress is made in recent years. However, most current treatments for cancers still involving surgery or chemo-, radiation, and hormone therapies. And chemical substances is associated with suppressing immune system by destroying immune cells, and with various toxicities (Kalyanaraman B et al., 2002; Naumov GN et al., 2003). Further, the development of drug resistance is linked with current treatments, and could be due to abnormalities in drug transporters or detoxifying enzymes that affect the interaction between chemotherapeutic agent and its target. Defects in DNA repair mechanisms and the apoptotic or cell death pathway could also lead to the development of cancer drug resistance. Thus, chemotherapy is moderately accepted by Chinese cancer patients due to no sufficient effectiveness and severe toxicities. And, the prognosis remains poor for Chinese patients with advanced cancer.

Immunotherapy is considered as an important treatment option for cancer patients. According to several studies, tumor-specific cellular and humoral immune responses occur in patients with cancer. However, immune evasion is a main problem in cancer patients, and it was reported that impairment of CD4+ T cells was a mechanism for this immune evasion (Alisa A et al., 2005 ). Several results from the analysis of mRNA arrays revealed that MHC class II is one of the most highly expressed genes in cancer tissue, compared with benign adjacent tissues. These MHC II molecules induce CD4+ T cell anergy (Crispe IN et al., 2006). And further, increases in immunosuppressive myeloid and lymphoid cell populations, suppression of natural killer cells, and impair the effector function of cellular immune responses in cancer patients (Arihara F et al., 2013; Chen Z et al., 2009; Hoechst B et al., 2009; Ilkovitch D et al., 2009). On the other hand, immunosuppressive cell populations, eg., T regulatory cells (Tregs) and myeloid-derived suppressor cells, are also considered to be important factors in cancer evasion. The number of Tregs in cancer patients is elevated in peripheral blood and cancer tissue (Ormandy LA et al., 2005), and the accumulation of infiltrated Tregs within the tumor was found to be correlated with disease progression and poor prognosis (Chen KJ et al., 2011; Gao Q et al., 2007 ). On this background, the combination of chemotherapy with immunotherapy is commonly attempted, and among these considerations, cytokines, peptides vaccines, and monoclonal antibodies, etc were being developed as potential treatments or approved cancer therapies that could improve the immune response against cancers. Interferon (IFN), a well known cytokine which induces an antitumor response by enhancing cytotoxicity, tumor antigen presentation and lymphocyte proliferation, and by blocking angiogenesis, was used in patients with cancer (Rougier P et al., 2007; Belardelli F et al., 2002; Singh RK et al., 1995), and demonstrated some clinical efficacy with good tolerance (Sun HC et al., 2006; Lin SM et al., 2004). IFN was also used in combination with chemotherapy, with cisplatin and 5-fluorouracil (5-FU), for advanced cancer (Patt YZ et al., 2003; Komorizono Y et al., 2003). It was reported that the complete response reached $16 \%$ and partial response $36 \%$ in cancer patients with portal venous invasion and treated by a combination of 5-FU and IFN (Obi et al., 2006). The combination of IFN and granulocytemacrophage colony-stimulating factor was tested and found to be effective in selected advanced cancer patients, suggesting that IFN could induce apoptosis and inhibit cell growth (Vadrot $\mathrm{N}$ et al., 2006). Another important cytokine with immunostimulatory functions is IL-2. The effect of IL-2 was clinically tested in patients with several cancer sites, eg., melanoma and renal cancer, for its ability to stimulate the proliferation and activity of T cells that would cause tumor regression (Rosenberg SA et al., 1998; Cheng Y et al., 2013). However, the utility of therapeutic peptides is limited by their susceptibility to degradation and poor tumor penetration in vivo (Talmadge JE et al., 1998). Thus, Lienal polypeptide is clinically tested in this study on the background that few previous reports were found.

In this study, our purpose is to assess the safety of Liena polypeptide injection (produced by JILIN FSENS PHARMACEUTICAL CO.,LTD) combined with chemotherapy in treating patients with advanced cancers. We recruited 20 female and 14 male patients with advanced cancer recruited into this study, including 10 patients with breast, 8 patients with colorectal, 8 patients with lung, 4 patients with gastric, and 1 patient with esophageal cancer, as well as 1 patient with nonHodgkin's lymphoma, 1 patient with low pharyngeal and 1 patient with urethral cancer. Liena polypeptide injection was intravenously injected at a dosage of $2 \mathrm{ml}$ plus $100 \mathrm{ml}$ normal saline for continuous 7 days during chemotherapy as one course. After at least two courses of treatment, safety and side effects were evaluated. Incidences of Grade 1 to 2 myelosuppression was observed in $5 / 34$ patients, and Grade 1 to 2 elevation of hepatic enzyme was recorded in $3 / 34$ patients. Adverse effects on the gastrointestinal tract were documented in $5 / 34$ patients, and were Grade 1. No Grade 3-4 toxicities were diagnosed. No treatment related death was found. In conclusion, our current study suggested that Liena polypeptide injection combined with chemotherapy was safe in treating several sites of tumors, that mainly included lung, colorectal and breast cancer. However, further study should be conducted to clarify the effectiveness of this treatment. 


\section{Acknowledgements}

Dr. Xin-En Huang is supported by Traditional Chinese Medicine Scientifi Research Project (LZ11091) and Jiangsu Province fourth stage "333 high- level Personnel Training Project" third levels of talent cultivating object.

\section{References}

Alisa A, Ives A, Pathan AA, et al (2005). Analysis of CD4+ T-Cell responses to a novel alpha-fetoprotein-derived epitope in hepatocellular carcinoma patients. Clin Cancer Res, 11, 6686-94.

Alving CR, Peachman KK, Rao M, et al (2012). Adjuvants for human vaccines. Curr Opin Immunol, 24, 310-5.

Arihara F, Mizukoshi E, Kitahara M, et al (2013). Increase in CD14+HLA-DR -/low myeloid-derived suppressor cells in hepatocellular carcinoma patients and its impact on prognosis. Cancer Immunol Immunother, 62, 1421-30.

Arruebo M, Fernández-Pacheco R, Ibarra MR, et al (2007). Magnetic nanoparticles for drug delivery. Nano Today, 2, 22-32.

Belardelli F, Ferrantini M, Proietti E, et al (2002). Interferonalpha in tumor immunity and immunotherapy. Cytokine Growth Factor Rev, 13, 119-34.

Bode C, Zhao G, Steinhagen F, et al (2011). CpG DNA as a vaccine adjuvant. Expert Rev Vaccines, 10, 499-511.

Brannon-Peppas L, Blanchette JO (2004). Nanoparticle and targeted systems for cancer therapy. Adv Drug Deliv Rev, 56, 1649-59.

Chen KJ, Lin SZ, Zhou L, et al (2011). Selective recruitment of regulatory T cell through CCR6-CCL20 in hepatocellular carcinoma fosters tumor progression and predicts poor prognosis. PLoS One, 6, e24671.

Chen W, Zheng R, Zeng H, et al (2014). Trend analysis of the changes of male/female, urban/rural incidences and average age of cancer patients in China 1989-2008. Chin J Oncol, 36, 796-800.

Chen Z, Shen S, Peng B, et al (2009). Intratumoural GM-CSF microspheres and CTLA- 4 blockade enhance the antitumour immunity induced by thermal ablation in a subcutaneous murine hepatoma model. Int J Hyperthermia, 25, 374-82.

Cheng M, Chen Y, Xiao W, et al (2013). NK cell-based immunotherapy for malignant diseases. Cell Mol Immunol, 10, 230-52.

Cheng Y, Zhang G, Li G (2013). Targeting MAPK pathway in melanoma therapy. Cancer Metastasis Rev, 32, 567-84.

Crispe IN, Giannandrea M, Klein I, et al (2006). Cellular and molecular mechanisms of liver tolerance. Immunol Rev, 213, 101-18.

Ferlay J, Shin H, Bray F, et al (). GLOBOCAN 2008, Cancer Incidence and Mortality Worldwide; IARC Cancer Base No. 10; International Agency for Research on Cancer: Lyon, France, 2010; Volume 2010, p. 29.

Gao Q, Qiu SJ, Fan J, et al (2007). Intratumoral balance of regulatory and cytotoxic $\mathrm{T}$ cells is associated with prognosis of hepatocellular carcinoma after resection. J Clin Oncol, $25,2586-2593$

Hoechst B, Voigtlaender T, Ormandy L, et al (2009). Myeloid derived suppressor cells inhibit natural killer cells in patients with hepatocellular carcinoma via the NKp30 receptor. Hepatology, 50, 799-807.

Ilkovitch D, Lopez DM (2009). The liver is a site for tumorinduced myeloid-derived suppressor cell accumulation and immunosuppression. Cancer Res, 69, 5514-21.

Jemal A, Bray F, Center MM, et al (2011). Global cancer statistics. CA Cancer J Clin, 61, 69-90.

Kalyanaraman B, Joseph J, Kalivendi S, et al (2002). Doxorubicininduced apoptosis: implications in cardiotoxicity. Mol Cell Biochem, 234-235, 119-124.

Komorizono Y, Kohara K, Oketani M, et al (2003). Systemic combined chemotherapy with low dose of 5-fluorouracil, cisplatin, and interferon-alpha for advanced hepatocellular carcinoma: a pilot study. Dig Dis Sci, 48, 877-81.

Lin SM, Lin CJ, Hsu CW, et al (2004). Prospective randomized controlled study of interferon-alpha in preventing hepatocellular carcinoma recurrence after medical ablation therapy for primary tumors. Cancer, 100, 376-82.

Liu L (2014). The global significance of China's cancer burden and control effort. Ann Transl Med, 2014, 2.

National Bureau of Statistics of China (2011). China Population and Employment Statistics Yearbook, China Statistics Press: Beijing, China, 2012.

Naumov GN, Townson JL, MacDonald IC, et al (2003). Ineffectiveness of doxorubicin treatment on solitary dormant mammary carcinoma cells or late-developing metastases. Breast Cancer Res Treat, 82, 199-206.

Obi S, Yoshida H, Toune R, et al (2006). Combination therapy of intraarterial 5-fluorouracil and systemic interferon-alpha for advanced hepatocellular carcinoma with portal venous invasion. Cancer, 106, 1990-7.

Ormandy LA, Hillemann T, Wedemeyer H, et al (2005). Increased populations of regulatory $\mathrm{T}$ cells in peripheral blood of patients with hepatocellular carcinoma. Cancer Res, 65, 2457-64.

Ozols RF, Herbst RS, Colson YL, et al (2006). Clinical cancer advances 2006: major research advances in cancer treatment, prevention, and screening - a report from the American society of clinical oncology. Jpn J Clin Oncol, 25, 146-62.

Patt YZ, Hassan MM, Lozano RD, et al (2003). Phase II trial of systemic continuous fluorouracil and subcutaneous recombinant interferon Alfa-2b for treatment of hepatocellular carcinoma. J Clin Oncol, 21, 421-7.

Peng XH, Qian X, Mao H, et al (2008). Targeted magnetic iron oxide nanoparticles for tumor imaging and therapy. Int $J$ Nanomedicine, 3, 311-21.

Rosenberg SA, Yang JC, Restifo NP, et al (2004). Cancer immunotherapy: moving beyond current vaccines. Nat Med, 10, 909-15.

Rosenberg SA (2001). Progress in human tumour immunology and immuno-therapy. Nature, 411, 380-4.

Rosenberg SA, Yang JC, White DE, et al (1998). Durability of complete responses in patients with metastatic cancer treated with high-dose interleukin-2: identification of the antigens mediating response. Ann Surg, 228, 307-19.

Rougier P, Mitry E, Barbare JC, et al (2007). Hepatocellular carcinoma (HCC): an update. Semin Oncol, 34, S12-20.

Schuster M, Nechansky A, Kircheis R (2006) . Cancer immunotherapy. Biotechnol $J, 1,138-47$.

Serda RE (2013) . Particle platforms for cancer immunotherapy. Int J Nanomedicine, 8, 1683-96.

Shurin MR, Naiditch H, Gutkin DW, et al (2012). ChemoImmunoModulation: immune regulation by the antineoplastic chemotherapeutic agents. Curr Med Chem, 19, 1792-803.

Singh RK, Gutman M, Bucana CD, et al (1995). Interferons alpha and beta down-regulate the expression of basic fibroblast growth factor in human carcinomas. Proc Natl Acad Sci USA, 92, 4562-6.

Sun HC, Tang ZY, Wang L, et al (2006). Postoperative interferon alpha treatment postponed recurrence and improved overall survival in patients after curative resection of HBV-related hepatocellular carcinoma: a randomized clinical trial. $J$ 
Cancer Res Clin Oncol, 132, 458-65.

Talmadge JE (1998). Pharmacodynamic aspects of peptide administration biological response modifiers. Adv Drug Deliv Rev, 33, 241-52.

Vadrot N, Legrand A, Nello E, et al (2006). Inducible nitric oxide synthase (iNOS) activity could be responsible for resistance or sensitivity to IFN-gamma-induced apoptosis in several human hepatoma cell lines. J Interferon Cytokine Res, 26, 901-13.

WHO. GLOBOCAN 2012: Estimated Cancer Incidence, Mortality and Prevalence Worldwide in 2012. Available online: http://globocan.iarc.fr (accessed on 17 May 2015). 